\title{
A Comparative Study of Etiology of Cut Injury Neck Amongst Tribals Presenting in Ent Department of A Tertiary Care Hospital of Jharkhand.
}

\author{
Dr. R.K.Pandey ${ }^{1}$, Dr. Ashit Toppo ${ }^{2}$, Dr. Deepak Kumar Sinha ${ }^{3}$ \\ Associate Professor ${ }^{l}$, Department of ENT, RIMS, Ranchi \\ Registrar ${ }^{2}$, Department of ENT, RIMS, Ranchi \\ Junior Resident Academic ${ }^{3}$, Department of ENT, RIMS, Ranchi.
}

\begin{abstract}
Introduction: Penetrating neck trauma involves trauma by a sharp object penetrating the skin and violating the platysma layer of the neck.These are both complex and challenging to manage. It is a common presentation in our hospital and their management requires a multidisciplinary approach.

Objective: To analyse the etiology of cut injury neck amongst the tribalspresenting in Ear Nose and Throat (ENT) Department Rajendra Institute of Medical Sciences (RIMS), RANCHI during the period from October2015 to December-2016.

Design of study: Retrospective study (Record based).

Materials and methods: Data for study were collected from the Medical Records Department,RIMS,Ranchi during the period October, 2015- December, 2016.Total sample size for this study was 45.Statistical analysis: Templates were generated in MS excel sheet and data analysis was done using SPSS software(version 20).Result: The study showed homicide60\%(n=27) being the most common cause of cut injury neck followed by suicide $26.7 \%(n=12)$ and accidents $11.1 \%(n=5)$.
\end{abstract}

Conclusion: A proper arrangement for the management of such cases in periphery is required as this will save many lives. Along with the above, attention towards the causes is also the need of the time.

Keywords: Cut injury neck, tribals, etiology.

\section{Introduction}

Worldwide, cut injuries of neck account for approximately $5 \%$ to $10 \%$ of all traumatic injuries with multiple structures being injured in $30 \%$ of patients. In developing countries the incidence is increasing at a fast rate partly because of increasing conflict over limited resources, poor socioeconomic status, poverty, unemployment, easy access to firearms, alcohol and substance misuse and increased crime rates ${ }^{1-3}$. All injuries to the neck are potentially lifethreateningbecause of the many vitalstructures in this area.In case of cut throatwound there may be possibility of injury tothe vital structures that may become rapidlyfatal due to profuse haemorrhage from damagedmajor blood vessels, air embolism or airwayobstruction. According to Roon and Christensen's classification $^{2}$, neck injuries are divided into three anatomical zones. Zone I injuries occur at thethoracic outlet, which extends from the levelof the cricoid cartilage to the clavicles. ZoneII injuries occur in the area between thecricoid and the angle of the mandible. Injurieshere are the easiest to expose and evaluate.Zone III injuries are between the angle of themandible and the base of the skull. Althoughzones I and III are protected by bones andthe vital structures in the zone II are notprotected by bone, so the risk of injury isdifferent in three zones.

Injuries to the neck can be both complex and challengingto treat. The management of these injuries requires a multidisciplinary approach requiring theclose association of the otolaryngologists, the vascular surgeons, the anesthetists and the psychiatrists ${ }^{7}$.Suicide is a known worldwide leading cause of death with psychiatric illnesses listed among the strongest predictors ${ }^{8}$. Other predictors listed are familial troubles and poverty ${ }^{9}$.Patients with attempted suicide should havea psychiatric consultation. This is becausethe act of suicide is a sign of underlying mentalillness and there is a possibility of a secondattempt. Ellis reported $25 \%$ of his patientsas having made a second attempt at suicide. Victims of homicidal cut-throat needpsychological support to overcome the traumato their psyche, which may linger long afterthe neck wounds heal.

\section{Materials And Methods}

This retrospective study included 45 cases of cut injury neck presenting in ENT department RIMS,Ranchi during the period October, 2015- December, 2016. Patients with minor superficial neck injuries not requiring admission were excluded from this study.Templates were generated in MS excel sheet and data analysis was done using SPSS software(version 20). 


\section{Results}

During the period from October 2015 to December 2016, from the 45 patients included in the study, homicide $60 \%(\mathrm{n}=27)$ was the most common cause of cut injury neck followed by suicide $26.7 \%(\mathrm{n}=12)$ and accidents $11.1 \%(\mathrm{n}=5)$.Table 1 depicts the etiology of the patients of cut injury neck.

Table 1.Categorization of cut injury neck on the basis of etiology.

\begin{tabular}{|l|l|l|}
\hline Etiology & Frequency $(\mathbf{N}=\mathbf{4 5})$ & Percentage $(\%)$ \\
\hline Homicidal & 27 & 60 \\
\hline Suicidal & 12 & 26.7 \\
\hline Accidental & 6 & 13.3 \\
\hline Total & 45 & 100 \\
\hline
\end{tabular}

Family disputes $(37 \%)$ were the most common cause amongst the homicidal cases while substance abuse $(41.7 \%)$ was the most common one for the cases of suicide. Road traffic accidents accounted for $66.7 \%$ of the accidental cases while accidental falls were the cause in $33.3 \%$ cases. The individual classification of the etiologies has been shown in the Table 2, Table3 and Table 4.

Table 2.Categorization of Homicidal cases.

\begin{tabular}{|l|l|l|}
\hline Categories & $\begin{array}{l}\text { Frequency } \\
(\mathbf{n = 2 7 )}\end{array}$ & Percentage (\%) \\
\hline Family Disputes & 10 & 37 \\
\hline Property Disputes & 8 & 29.6 \\
\hline Theft & 5 & 18.6 \\
\hline No Specific Cause Explained & 4 & 14.8 \\
\hline
\end{tabular}

Table 3.Categorization of Suicidal cases.

\begin{tabular}{|l|l|l|}
\hline Categories & Frequency $(\mathbf{n = 1 2})$ & Percentage $(\%)$ \\
\hline Substance Abuse & 5 & 41.7 \\
\hline Family disputes & 4 & 33.3 \\
\hline Major Psychiatric Illness & 2 & 16.7 \\
\hline Significant Losses in Life & 1 & 8.3 \\
\hline
\end{tabular}

Table 4.Categorization of Accidental cases.

\begin{tabular}{|l|l|l|}
\hline Categories & Frequency $\mathbf{( n = 6 )}$ & Percentage $\mathbf{( \% )}$ \\
\hline Road Traffic Accidents & 4 & 66.7 \\
\hline Accidental Falls & 2 & 33.3 \\
\hline
\end{tabular}

\section{Discussion}

In our study, we came up with the result that homicide $60 \%(\mathrm{n}=27)$ was the most common cause of cut injury neck amongst the tribal population of Jharkhand, coming from the rural areas of the state, followed by suicidal cases $26.7 \%(\mathrm{n}=12)$, rest being accidental $13.3 \%(\mathrm{n}=6)$.In a similar study by Ozdemir, the cases were $80 \%$ homicidal and $20 \%$ suicidal. None of the cases were of accidental origin ${ }^{8}$. In a study by Aich et al.on hospitalized cut throat injury patients, 48 (71.64\%) were due to homicidal injury, $12(17.91 \%)$ were victims to accidental injury, and only $7(10.44 \%)$ persons went for suicidal attempt ${ }^{9}$.

The homicides were due to family disputes (37\%), property disputes (29.6\%), for theft (18.6\%), and in $14.8 \%$ cases no specific cause could be identified. Substance abuse (41.7\%), family disputes (33.3\%), major psychiatric illness (16.7\%) and significant personal losses (8.3\%) were the causes found for the suicidal cases. Amongst the accidental cases, road traffic accidents were most common (66.7\%) while accidental falls lead to $33.3 \%$ of the same.

In a study, on patients who had cut throatinjuries done in Tanzania, interpersonal conflict (24.4\%) was the most common factor found for homicidal injuries while psychiatric illness(16.2\%) and road traffic accidents $(9.2 \%)$ were the most frequent ones for the suicidal attempts and accidental injuries, respectively ${ }^{10}$. In a similar study by Ozdemir, the most dominant reason turned out to be mental illness with a prevalence of $26.7 \%$,injuries due to honor reasons were second in order with $20 \%$, the other reasons being domestic violence (13\%), economical reasons (13\%), and gang fights $(7 \%)^{8}$

All the patients included in our study were tribals from the rural areas of Jharkhand and were of low socio-economic class. Most of the people involved in the cases were addicted to one or the other product and many cases were finally reported to have been concluded under the effect of those.

Our study also shows the large number of cases of cut injury neck being referred to the tertiary centre of Jharkhand from other primary and secondary levels. This pointstowards the situation of peripheral health system in Jharkhand, which has no proper facility for management of such cases which are quite frequent in the state. 


\section{Conclusion}

According to the results of our study it is supposed that the early appropriate measures could save lives in vastmajority. Addressing the root causes of violence such as poverty, illiteracy, unemployment and substance abusewill reduce the incidence of cut throat injuries in our society. Providing the efficient emergency health care servicesfor primary care and effective ambulance system for immediate transport of cut throat victims to hospitalwill decrease time delay in reaching the hospital. Stringent and appropriate measures by the government agenciesfor enforcement of law and order will reduce the burden of homicidal cut throat in near future ${ }^{9}$.

\section{Acknowledgements}

We express our heartfelt gratitude towards the staff of ENT Department, RIMS for their immense support in collection of data and management of the cases.

Financial support and sponsorship: Nil.

Conflicts of interest: None.

Ethical approval: The study was approved by Institutional Ethics Committee.

\section{References}

[1]. Penden, M., McGee, K. and Sharma, G. (2002) The Injury Chart Book: A Graphical Overview of the Global Burden ofInjuries. World Health Organization, Geneva.

[2]. Fagan, J.J. and Nicol, A.J. (2008) Neck Trauma. In: Gleeson, M., Ed., Scott-Brown's Otorhinolaryngology, Head andNeck Surgery, 7th Edition, Great Britain, Hodder Arnold, 1768.

[3]. Bhattacharjee, N., Arefin, S.M., Mazumder, S.M. and Khan, M.K. (1997) Cut Throat Injury: Retrospective Study of 26

[4]. Cases.Bangladesh Medical Research Council Bulletin, 23, 87-90.

[5]. Herzog M, Hoppe F, Baier G, Dieler R. Injuries of the head and neck in suicidal intention. Laryngorhinootologie. 2005;84(3):17681. doi: $10.1055 / \mathrm{s} 2004825873$. [PubMed] [Cross Ref]

[6]. Nock MK, Hwang I, Sampson N. CrossNationalAnalysis of the Associations among Mental Disorders and Suicidal Behavior: Findings from the WHO World Mental Health Surveys. PLoS Med. 2009;6(8):e1000123. doi: 10.1371/journal.pmed.1000123. [PMC free article] [PubMed] [Cross Ref]

[7]. Bhattacharjee N, Arefin SM, Mazumder SM, Khan MK. Cut throat injury: a retrospective study of 26 cases. Bangladesh Med Res Counc Bull. 1997;23(3):87-90. [PubMed]

[8]. Kundu, R.K., Adhikary, B. and Naskar, S. (2013) A Clinical Study of Management and Outcome of 60 Cut Throat Injuries.

[9]. Ozdemir B, Celbis O, Kaya A. Cut throat injuries and honor killings: review of 15 cases in eastern Turkey. J Forensic Leg Med 2013;20:198-203.

[10]. Aich M, Khorshed-Alam AB, Talukder DC, RoufSarder MA,Yousuf Fakir A, Hossain M. Cut throat injury: Review of 67 cases.Bangladesh J Otorhinolaryngol 2011;17:5-13.

[11]. Gilyoma JM, Hauli KA, Chalya PL. Cut throat injuries at a university teaching hospital in northwestern Tanzania: A review of 98 cases. BMC Emerg Med 2014 14;14:1. 